\title{
Submicron Bonding Technology with Passive Alignment for Optical Modules
}

\author{
Akira YAMAUCHI* \\ 光通信モジュール高精度パッシブ実装技術 \\ 山内 朗*
}

*東レエンジニアリング株式会社 エレクトロニクス事業本部ファインプロセス事業部（５ 520-2141 滋賀県大津市大江 1-1-45）

* IC Packaging Technology \& Development Dept., Electronics Div., Toray Engineering Co., Ltd. (1-1-45 Oe, Otsu-shi, Shiga 520-2141)

\begin{abstract}
概要 光通信モジュールの実装組立において, コストダウンと生産性の面からパッシブアライメント方式が求められてい る。このときの実装精度はサブミクロン台が要求されるが, 従来の実装装置では $\pm 5 \mu \mathrm{m}$ と精度上の限界があった。本稿では, パッシブアライメント方式のボンダーにおいて, 高精度実装を達成させるために実施した, LD素子とシリコン基板のそれぞ れの対向する電極面につけられた基準マークの認識精度向上対策, 振動対策, 熱膨張対策それぞれについて報告する。特に熱 膨張対策については, 室温や装置温度が $1^{\circ} \mathrm{C}$ 変化すると $1 \mu \mathrm{m}$ の割で実装ずれを生じるが, この温度変化による䛊差を補償する キャリブレーション方法を開発した。実際の実装精度の検証結果についても報告する。
\end{abstract}

\begin{abstract}
In the field of optical module assemblies, there is a demand for the passive alignment method, which is considered to contribute both to the cost reduction and the throughput enhancement. Although the optical modules require submicron level bonding accuracy, the conventional bonders can offer no better than $\pm 5 \mu \mathrm{m}$ level accuracy. In this paper, upgrading technologies for passive alignment bonder are reported, i.e. enhanced recognition accuracy of fiducial marks which are placed on the electrode surfaces of LD chips and silicon substrate respectively, anti-vibration structures, and anti-thermal expansion solutions. On the third issue, particularly, a new calibration method has been developed to compensate the thermal expansion that causes $1 \mu \mathrm{m}$ positional shifting at $1^{\circ} \mathrm{C}$ temperature change in the atmosphere or of the machine. Verification of test results on mounting accuracy is also reported.
\end{abstract}

Key Words: Passive Alignment, Flip Chip Bonder, Heat Expansion, Calibration, Optoelectronic Device, MEMS

\section{Introduction}

As shown in Fig.1, in the recent field of optical module assemblies, there is an increasing demand for replacing the conventional active alignment method with the passive alignment method, which is widely considered to contribute to the module assemblies both in cost reduction and throughput enhancement at the same time. Optical modules require submicron level flip-chip bonding of laser diode elements onto silicon substrates as the basis for fixing the optical fibers. ${ }^{1), 2)}$

\section{Passive Alignment Method by Two-Sight Cam- era}

In the first place, the process how the LD chips are aligned and mounted on silicon substrates using passive alignment is briefly explained. As shown in Fig. 2, the chip before bonding is held by the bonding head and the substrate is also held on the bonding stage. In order to perform alignment, the two-sight camera unit is inserted between the chip and the substrate, and it recognizes their positions, enabling any positional shift to be adjusted by the stage $x, y, \theta$-movement. After the retraction of camera unit, the bonding head

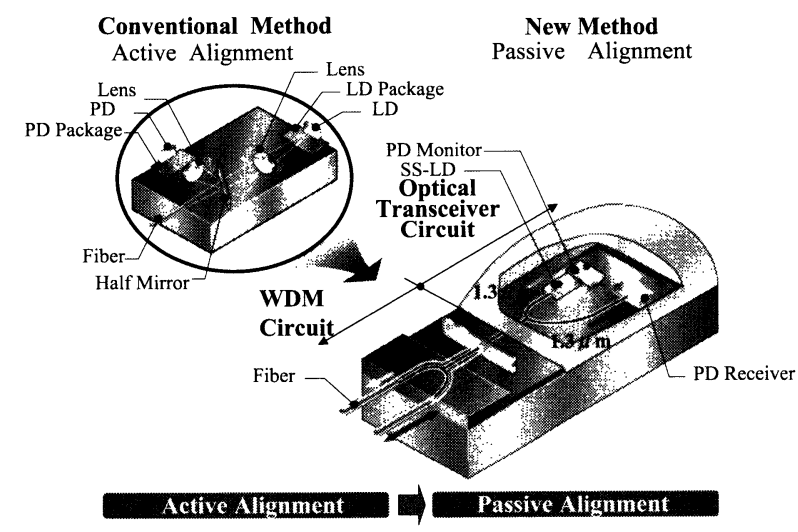

Fig. 1 Transition of optical module assembly 


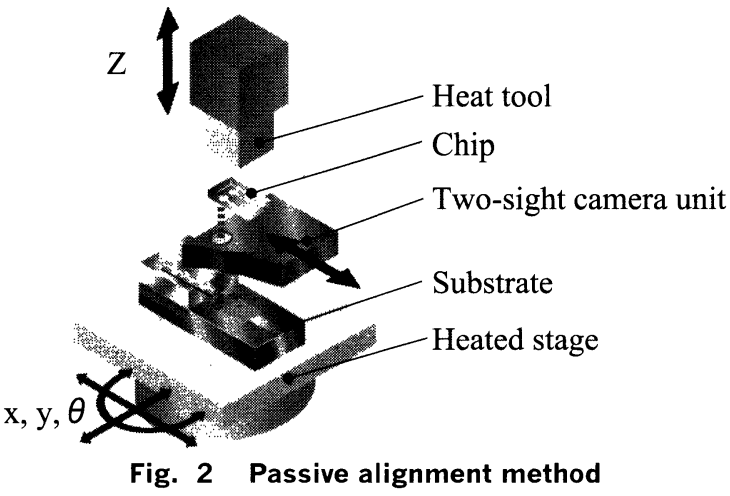

is lowered and then heating, pressurization, bonding (defusing) and cooling processes take place in due order.

The employment of two-sight camera has two advantages. Firstly, not only the heat tool but the heated stage of nontransparent material such as ceramics can be used to allow optimal bonding conditions for temperature profile control. Secondly, there are no such requirements as chips having well-polished surfaces for carrying out fluoroscopic recognition of alignment marks.

\section{Upgrading Alignment Accuracy of Chip Bond- ing}

Next, it will be discussed on how the range of \pm 5 $\mu \mathrm{m}$ accuracy for conventional flip-chip bonders has successfully been enhanced to the submicron level. The detailed explanations for this improvement are shown in sections 3.1 through 3.4. In pursuing the submicron level accuracy, it is necessary to investigate countermeasures to deal with both issues of vibration and thermal expansion. The thermal expansion issue is particularly essential. Bonding is achieved by aligning the chip and the substrate at the submicron level, but the accuracy of this bonding process cannot be ensured simply by enhancing the accuracy of the recognition process and of the alignment table mechanism. This is because heating and compression are applied from the top and bottom at a high temperature of $350^{\circ} \mathrm{C}$, when eutectic bonding is performed using an $\mathrm{Au} / \mathrm{Sn}$ bump material. The positional shifting caused by thermal expansion easily exceeds the required alignment accuracy.

\subsection{Enhanced Recognition Accuracy}

The first point is to enhance the recognition accuracy.

1) Upgraded resolution of vision system

One of the most effective measures employed in the

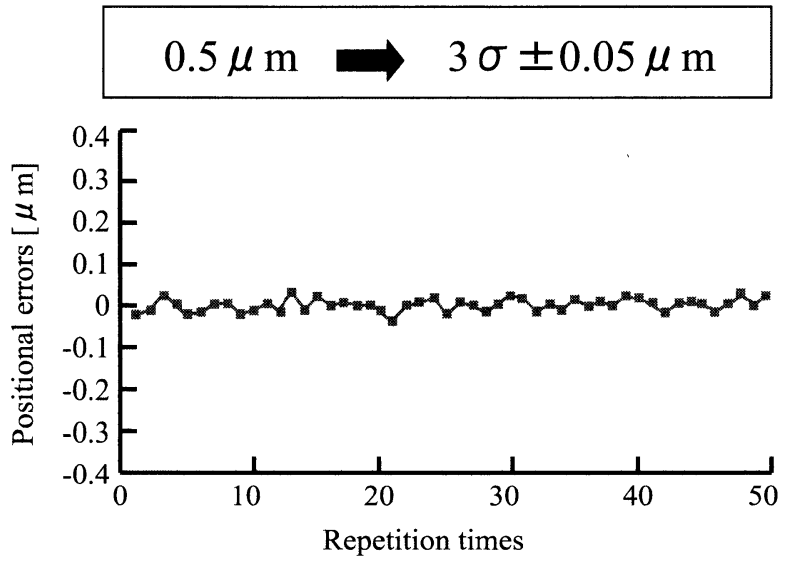

Fig. 3 Upgraded resolution of vision system

system is "vector matching method" to improve image-processing accuracy. By achieving a greater amount of vision information correction, the vector matching method realizes ten times the accuracy of the conventional pattern matching method, and this ensures $0.05 \mu \mathrm{m}$ accuracy of fiducial mark recognition without reducing $0.6 \mathrm{~mm}$ square field of view $^{3)}$, as shown in Fig. 3.

2) Recognition tolerance for fiducial mark status

Second element is the reading tolerance affected by the distorted or chipped markings. Numerous tests have been conducted and the reading tolerance is verified to be available when marks are reduced to $75 \%$, $60 \%$ or even $50 \%$.

3) Correction of lens distortion

The third element considered is the correction of lens distortion. Recognition accuracy within $0.14 \mu \mathrm{m}$ is obtained in any area of the lens by applying unique software that records and corrects lens distortion, as shown in Fig. 4.

4) One-sight alignment

Enhancement of the accuracy of the image processing and reduction of the lens distortion discussed as above also contributes to enlarging the recognition area of the camera, which enables alignment to be performed without moving the camera. With this method, there is no need to be concerned about the mechanical tolerance of the recognition camera along the $X$ and $Y$ axes.

\subsection{Anti-Vibration Structure}

There are two types of vibration: one that is caused by the alignment table operation, and the other that is caused by outside factors. For the submicron machine performance, both types of vibration may impact the operation. 


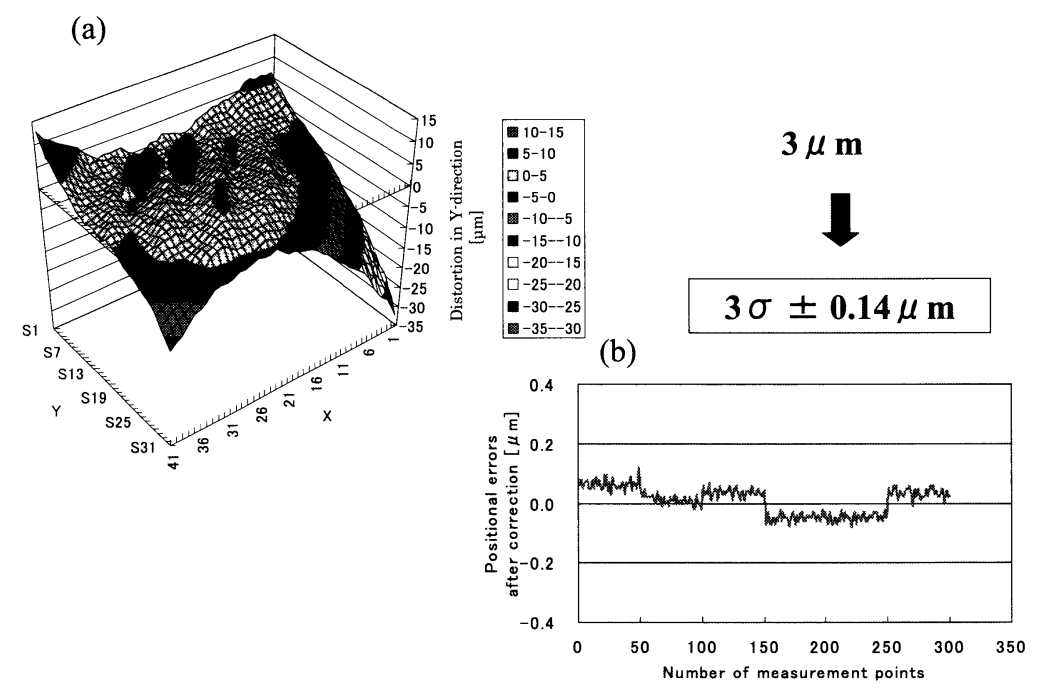

Fig. 4 Correction of lens distortion

1) Active anti-vibration system

"Active anti-vibration system" is installed. This system not only reduces vibration caused from outside factors but has a function to generate reverse phase vibration so as to cancel the vibration created from inside the machine. The combination of the two functions completely eliminates vibration in the $\mathrm{X}, \mathrm{Y}$ and $\mathrm{Z}$ directions.

2) Anti-vibration measures for servomotors

Furthermore, the alignment table employing the linear servomotor tends to hunt by as much as \pm 1 pulse; therefore it cannot be denied that it would affect the accuracy. To solve this, alignment tables are composed of two sections: the rough and the final alignment tables. After ceasing servomotor operation of the rough alignment table, the final alignment table, using piezo actuator performs the alignment. In this way, the hunting effect of servomotor is eliminated.

\subsection{Anti-Thermal Expansion Solution}

1) Thermal expansion of heating tool

Here, the various effects of heat are discussed. The temperature of the heater during the bonding process is as high as $350^{\circ} \mathrm{C}$, causing thermal expansion of the heater, the chip, the substrate, and the heated stage. The thermal expansion changes into the pressure on the solder bumps and causes chip misalignment. The heat generated by the heater is accumulated and conducted to the bonding head and the stage, resulting in the warp of the equipment itself. Thermal expansion of the heater affects not only in the height ( $Z$ direction) but also in the $X$ and $Y$ directions, so even if high-accuracy alignment is achieved, shifting may occur during bonding process. As shown in Fig. 5, when heated up to $350^{\circ} \mathrm{C}$, the conventional heater causes distortional shifting of $25 \mu \mathrm{m}$ in the $\mathrm{Z}$ direction and $5 \mu \mathrm{m}$ in the $\mathrm{X}$ and $\mathrm{Y}$ directions.

The high response ceramic heater is specially developed for this particular bonding equipment. The structure of this ceramic heater is shown in Fig. 6. By employing a special laminated multi-layer structure for this ceramic heater, thermal expansion and distortion are successfully minimized, while maintaining high response. Thanks to the heat insulation structure, it is as low as $33^{\circ} \mathrm{C}$ at the point $25 \mathrm{~mm}$ below the mounting surface (heater tool tip shown at the top side of the figure) where the temperature is at $218^{\circ} \mathrm{C}$. Adjusting thermal expansion coefficient to be the same among the laminated multi-layers, distortionless structure of the heater is obtained in addition to the high response and thermal insulation structure.

This structure also reduces heater elongation from $25 \mu \mathrm{m}$ in the $\mathrm{Z}$ direction due to thermal expansion down to $5 \mu \mathrm{m}$. As less distortion occurs in bending direction, shifting in the $X$ and $Y$ directions (at the center of tool-tip where the chip is suction-held) is also reduced from $5 \mu \mathrm{m}$ to $0.4 \mu \mathrm{m}$, as shown in Fig. 6. The influence of misalignment in the $X$ and $Y$ directions resulting from tool warping is of particular importance for high positional accuracy. Regardless of the degree of the machining accuracy, the tool becomes elongated and distorted -like melted candy- during heating, thus causing misalignment of the chip. However, as the thermal expansion coefficient for each layer among multi-layer structure is identical, warping does not occur, and misalignment in the $X$ and $Y$ directions is minimized. ${ }^{4)}$ 


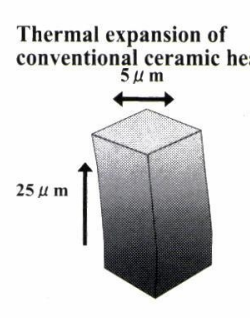

(a)

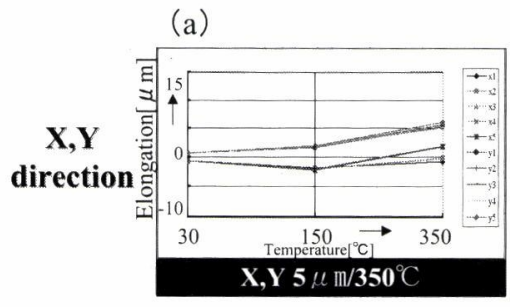

(b)

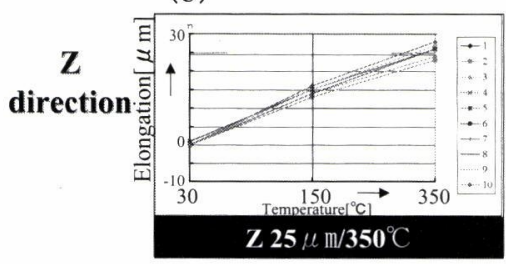

Fig. 5 Thermal expansion of ceramic heater

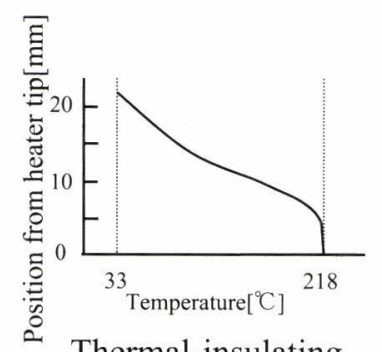

Thermal-insulating Structure minimizes elongation.

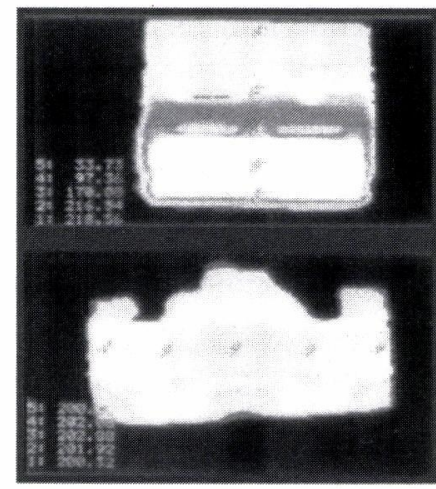

Fig. 6 Multi-layer ceramic heater structure

2) Cancellation mechanism of thermal expansion

An air floating bonding head like the one shown in Fig. 7 was developed to absorb total elongation of heat tool, heat stage, chip and substrate. This head is equipped with an air slide in its sliding section, holding the head in a perfectly floating state by providing counter-directional compressed air so that the weight of the head and tool is counterbalanced. Heating is done in such a floating state that the total thermal expansion of the chip, the substrate, the heat tool and the heated stage is cancelled. The pressurization level can be controlled within $5 \pm 1$ gf. Fig. 7 also shows the temperature profile during bonding process and the amount of head elongation due to thermal expansion. ${ }^{3)}$

When the solder bumps are heated and begin to melt in the case of soldering process, the floating state enables the reduced and controlled pressurization even in the presence of the thermal expansion. And,
Thermal expansion of

laminated ceramic heater

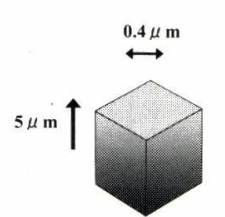

(c)

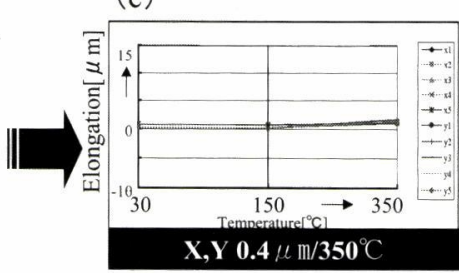

(d)

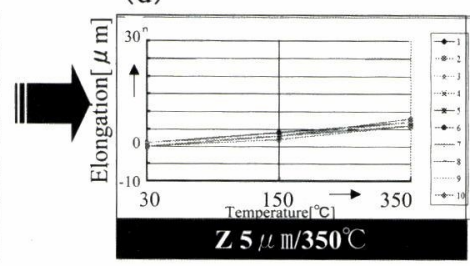

or ceramic heater

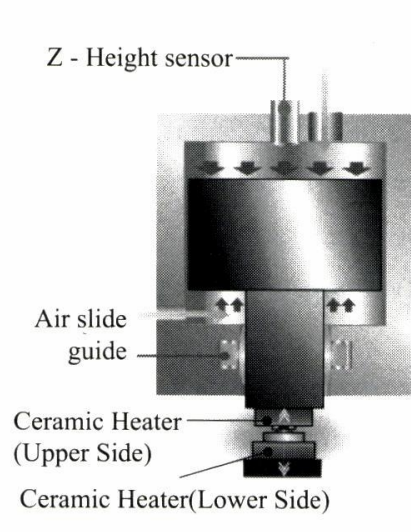

Ceramic Heater(Lower Side)

Fig. 7 Extreme-low pressure control eliminating thermal expansion influence the solder bump height is kept controlled by height sensor, until the cooling process and solidification starts.

3) Thermal expansion solution of camera unit

The effects of heat are not limited to the vicinity of the heater, the chip and the substrate. The two-sight camera unit, which is located between the two heaters, is also severely affected by the heat. As shown in Fig. 8 , the upper and lower image fields are grabbed by individual CCD cameras via respective prisms. This camera box itself is affected by heat, and as can be seen in the illustration, once the power is turned on, the temperature varies by about $5^{\circ} \mathrm{C}$ during a day operation. It is also obvious that the bonding error of 5 $\mu \mathrm{m}$ is magnified in proportion to the temperature variation. 


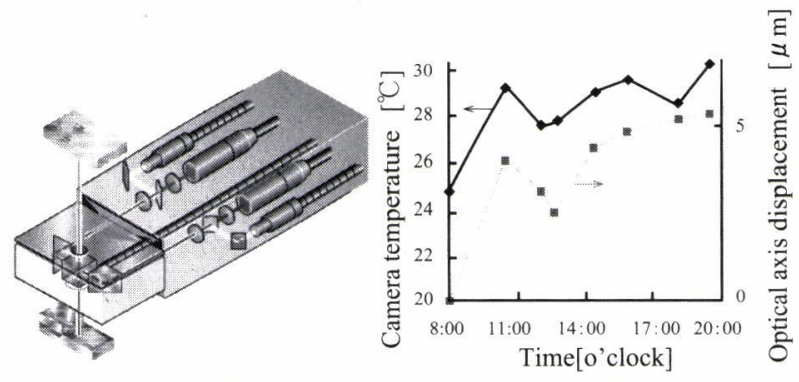

Fig. 8 Thermal expansion solution

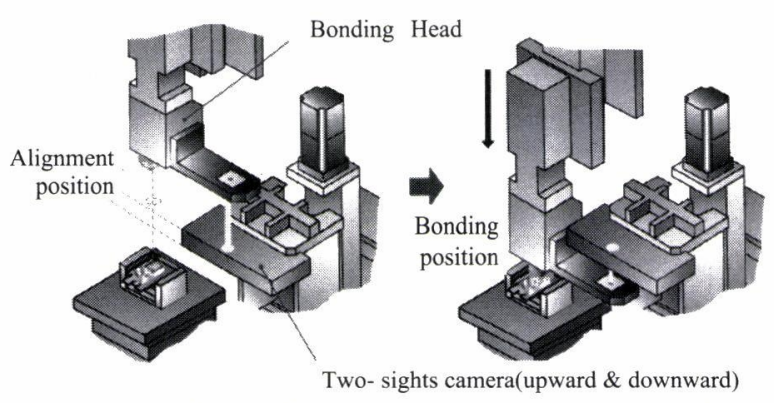

Fig. 9 Calibration using two-sight camera unit

This error caused by heat expansion is thought to turn into the positional recognition errors in alignment process. A calibration method has been developed that corrects the thermal drift caused by heat expansion. Next, the two-sight camera calibration method that uses reference marks will be discussed.

4) Calibration using two-sight camera unit, as shown in Fig. 9

In order to detect any discrepancy between the position where the chip is recognized and the position where the chip is actually bonded, a jig provided with a reference mark is fixed on the side of the bonding head. The reference mark is printed on a transparent glass plate so that it can be observed from above and below using two-sight camera. The upper camera first gets the image of the reference mark at the head height at which the recognition of the chip mark is done. Then, the reference mark image is taken by the lower camera at the position where the head is lowered to perform bonding. Thus, the positional error is figured out as the difference between the positions recognized by the upper and lower cameras.

By feeding back the calibration data to the next bonding, the alignment accuracy is maintained.

While the calibration method described above is still effective for maintaining bonding accuracy within a few microns, it is not applicable for submicron level accuracy. The repeatability of the conventional method, as shown in Fig. 10, is in the range of \pm 0.8 $\mu \mathrm{m}$, which is insufficient for submicron level align-

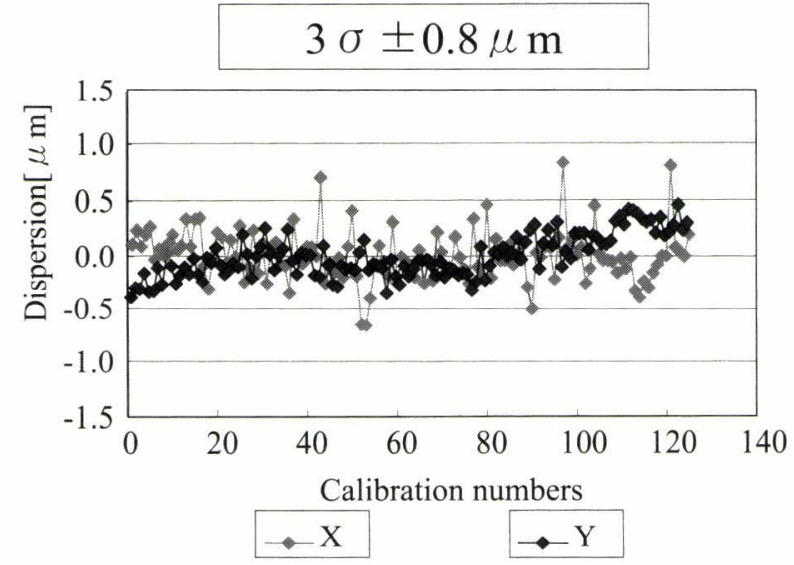

Fig. 10 Calibration accuracy using two-sight camera

ment accuracy.

This method has three potential issues. The first is that the upper camera must retract after reading the reference mark, and then the lower camera moves in again to take its image. In short, the issue is the repeatability of this in-and-out movement of the camera. The second issue is that the jig with the reference mark is moved in and out by a cylinder during the calibration process, and this also involves the risk of error occurrence. The third one is that the recognition image must be taken by the camera with the head in an overhanging position, which differs from the actual chip bonding.

5) Calibration using three-camera system, as shown in Fig. 11

A solution to these issues is a new calibration method that uses three cameras to determine the discrepancy between the positions where the chip and the substrate are recognized and the position where bonding actually takes place. In this method, a glass substrate with reference marks is fixed next to the heated stage. In the same way as the conventional method, a
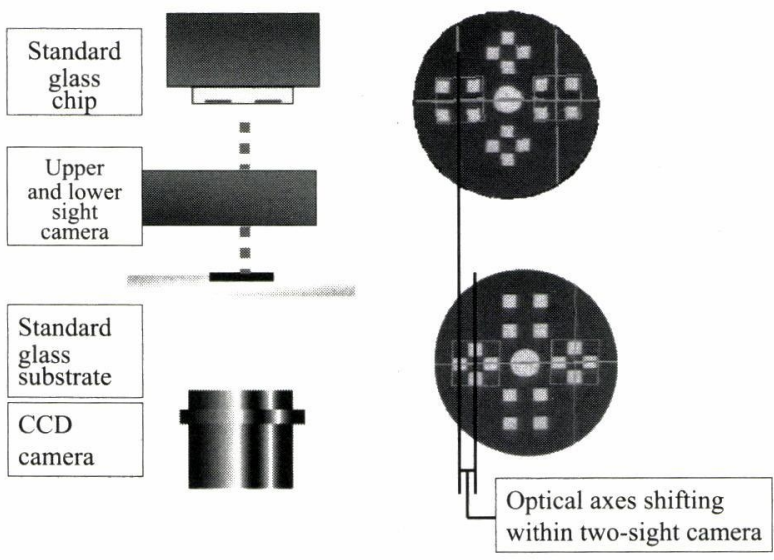

Fig. 11 Calibration using three cameras 


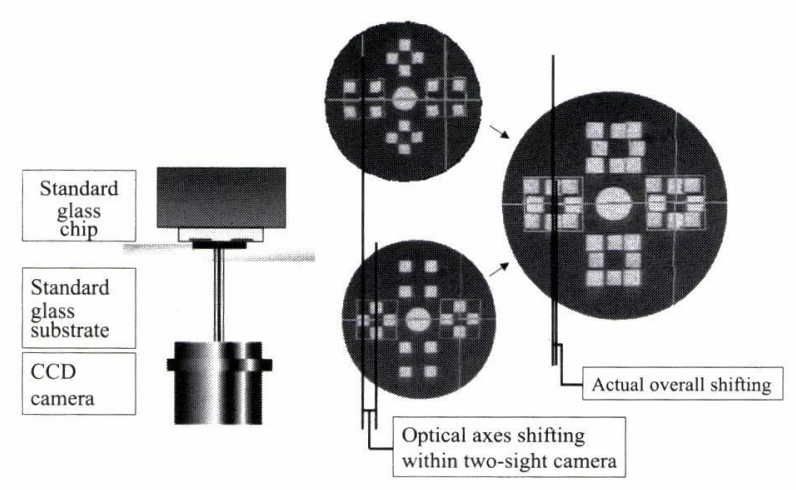

Fig. 12 Calibration using three cameras

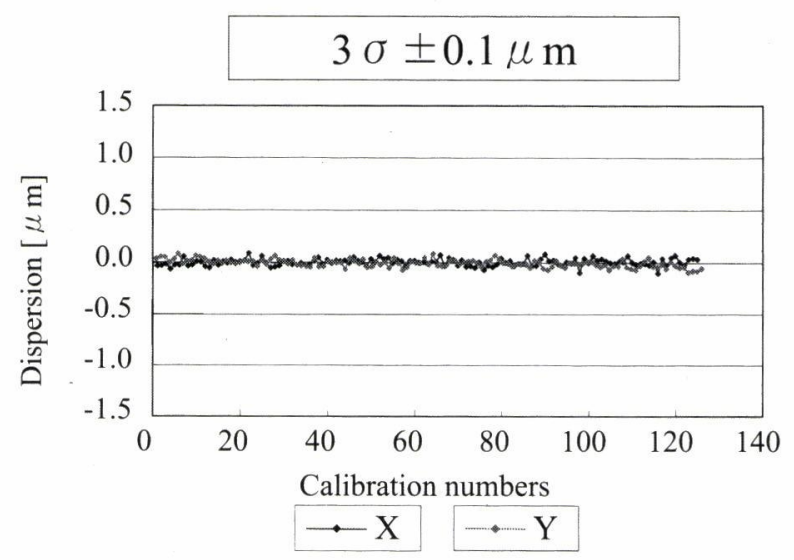

Fig. 13 Calibration accuracy using three cameras

standard glass chip with reference marks is suctionheld on the head. The two-sight camera unit goes between the standard chip and standard substrate, and then reads the fiducial marks with its upper and lower cameras. The relative positional differences of the upper and lower fiducial marks are then stored in memory. Next, the camera unit is retracted, the head is lowered, and the standard chip is mounted onto the standard glass substrate.

As shown in Fig. 12, the third camera reads fiducial marks on the chip and the substrate, and then recognizes the original position (with the image passing through the glass substrate). Positional errors are obtained by comparing the original position with the relative alignment position that has been stored in the recognition unit. This is the range of shifting caused by thermal expansion. In the subsequent bonding, this shifting is corrected by changing the relevant software parameters.

The Fig. 13 explains that the repetitive accuracy of this calibration method using three cameras, comparing with the calibration based on conventional reference marks, has sufficient reliability in keeping the tolerance of $\pm 0.1 \mu \mathrm{m}$ for submicron level bonding.

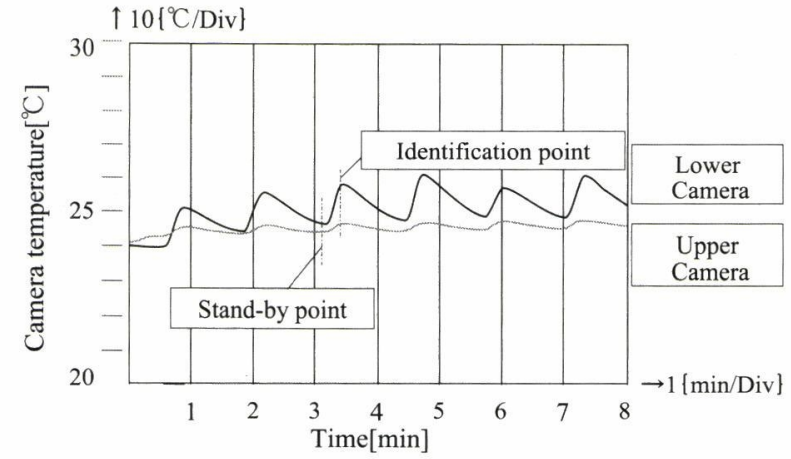

Fig. 14 Camera temperature in one alignment cycle

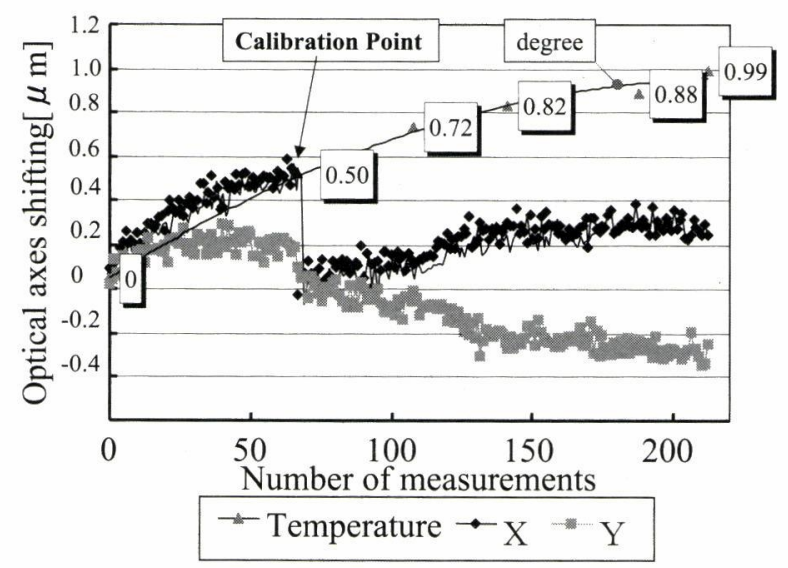

Fig. 15 Calibration for resetting optical axes shifting caused by camera temperature variation

6) Automatic calibration against camera temperature variation

The fluctuations in the temperature of the camera during repetitive bonding are shown in Fig. 14. Because the camera is frequently being positioned close to the heaters, there is considerable temperature fluctuation even within a single bonding operation. The temperature of the camera rises as it approaches the heaters and falls as it retracts. The camera is subject to gradual temperature changes in the repetitive alignment operations, and this suggests the necessity of calibration for every alignment cycle.

In order to make the camera system less susceptible to the thermal influence, air is constantly supplied of which temperature is controlled within the range of $0.08^{\circ} \mathrm{C}$. This air conditioning system prolonged the required interval of calibration to approximately one hour.

Fig. 15 shows the optical axes shifting converted into the bonding position during operation. As can be seen, a temperature variation of $0.5^{\circ} \mathrm{C}$ at the 70 th bonding triggered a calibration, and shifting of $0.5 \mu \mathrm{m}$ in the bonding position was canceled to zero. As shown in Fig. 16, the system is set to automatically perform this 


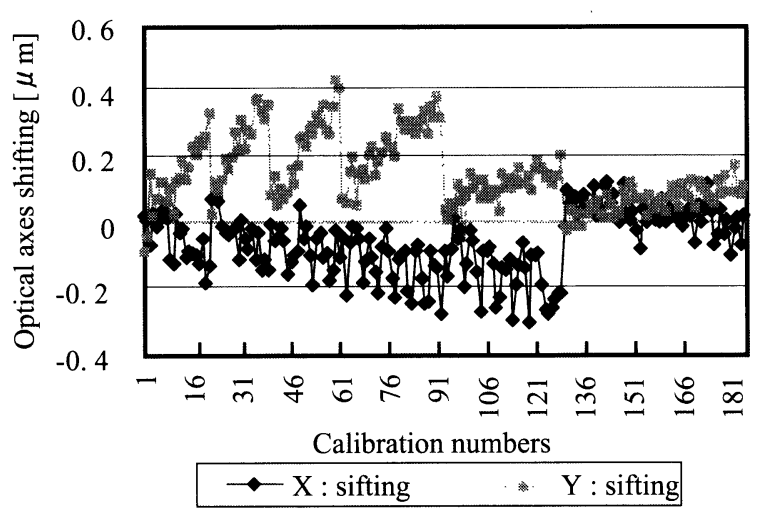

Fig. 16 Optical axes shifting controlled by automatic calibration/during 2 hours after setup

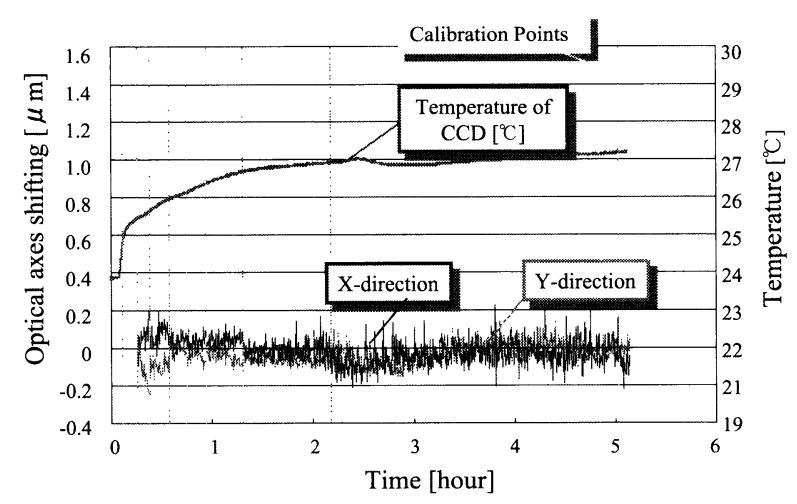

Fig. 17 Optical axes shifting controlled by automatic calibration/one-day operation

calibration each time temperature variation of $0.5^{\circ} \mathrm{C}$ is detected by a thermometer installed on the camera system. Thus, it is possible to maintain high alignment accuracy during operation. Fig. 17 shows an actual example of a day operation. By performing calibration automatically for any $0.2^{\circ} \mathrm{C}$ variation in temperature, which is called self-correction function, alignment accuracy within $\pm 0.2 \mu \mathrm{m}$ is certified.

\subsection{Solution of Positional Shifting during Bond-} ing

1) Horizontal repeatability of bonding head

In a "stepper" application for example, improvement of the optical system and the positioning table as described above would be sufficient. In the bonder application, however, it is not the case. No matter how accurate the initial alignment is, there remains the issue of positional shifting during actual chip bonding, where the chip is lowered into place and pressurized.

Now, the repetitive accuracy of bonding head descending shall be discussed. This is because of the inferior repeatability of the Z-axis (vertical) guide for the head. In the bonder application, the rigidity of the guide unit has been increased, and the repeatability within $\pm 0.025 \mu \mathrm{m}$ is obtained.
2) Co-planarity of bonding head against substrate

Secondly, the co-planarity of bonding head will be discussed, since this factor has impact on the parallel accuracy between the chip and the substrate. The chip and the substrate should be exactly in parallel when bonded, otherwise the chip may slip out of place.

Therefore, this system has been designed so that bonding surface orientation of the head can be controlled by 2-axis NC with the resolution of $0.2 \mu \mathrm{m}$. This function is also effective when exchanging bonding tools according to the chip size, enabling to correct subtle deviation from co-planarity in some applications such as multi-chip and multi-position bonding.

\section{Verification of Mounting Accuracy}

Next, in order to verify bonding accuracy, alignment and bonding test is executed using the standard glass chip and the standard glass substrate. The bonding misalignment is measured with the camera positioned below the substrate. The test result is shown in Fig. 18, where mounting accuracy in 125 times of bonding operations is measured with bonding pressurization of $0.98 \mathrm{~N}$ (100 gf) and without heating. High accuracy at submicron level is maintained: $0.12 \mu \mathrm{m}$ in the $\mathrm{X}$-direction and $0.09 \mu \mathrm{m}$ in the Y-direction, 3 sigma $(\sigma)$.

Furthermore, bonding accuracy is verified with heating at $350^{\circ} \mathrm{C}$ in the same way. The result is shown in Fig. 19, where deviations of values in both the $X$ and $Y$ directions are within $\pm 0.2 \mu \mathrm{m}$. In the Y-direction, however, the actual bonding position is shifted from the desired bonding position, the cause of which is thought to be the thermal expansion.

Lastly, the result of soldering interconnection of silicon chip with silicon substrate is discussed. An infrared camera is used for post-bonding inspection, which enables the direct observation of the bonded

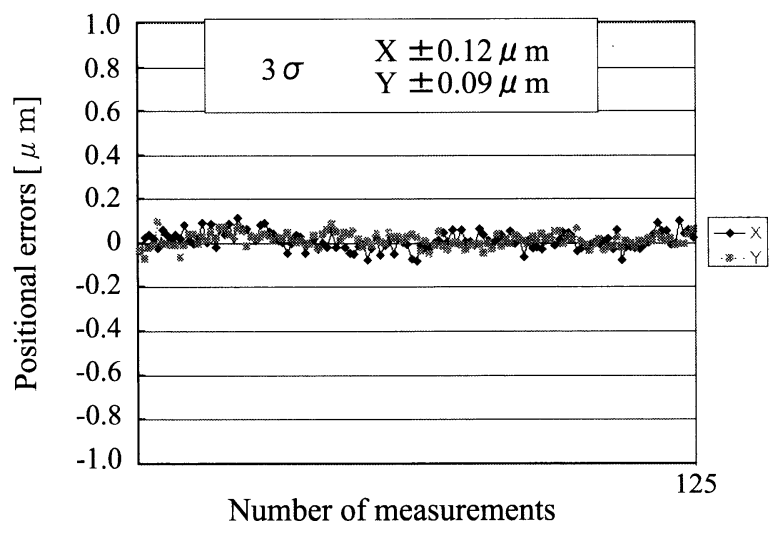

Fig. 18 Mounting accuracy test without heating 


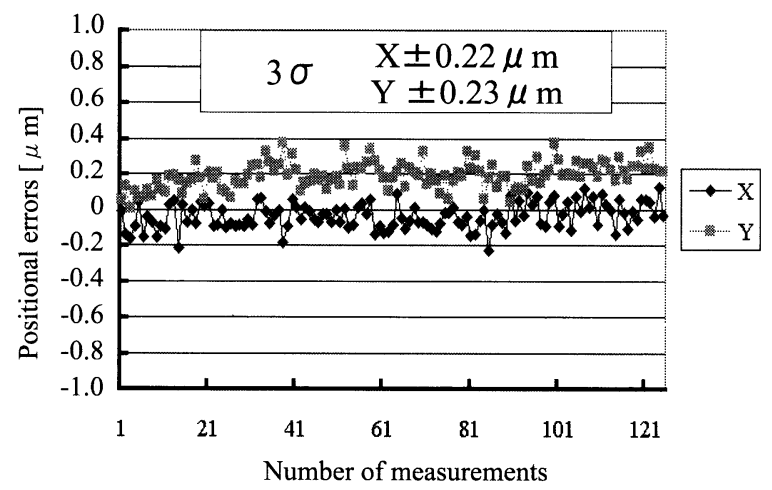

Fig. 19 Mounting accuracy test with heating at $350^{\circ} \mathrm{C}$

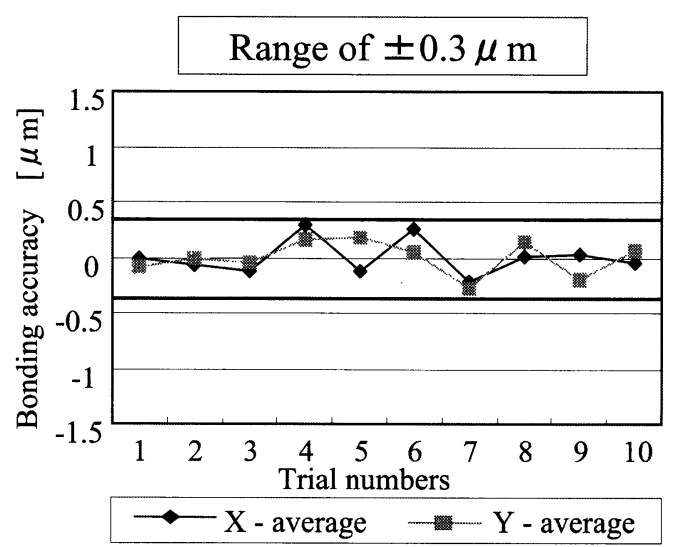

Fig. 20 Bonding accuracy at $280^{\circ} \mathrm{C}$

chip and substrate. As shown in Fig. 20, the bonding accuracy at the temperature of $280^{\circ} \mathrm{C}$, lower than the melting point of the solder, is within the range of \pm 0.3 $\mu \mathrm{m}$. On the other hand, the bonding accuracy at $300^{\circ} \mathrm{C}$, higher than the melting point, is within the range of $\pm 0.5 \mu \mathrm{m}$ as shown in Fig. 21. The difference of \pm 0.2 $\mu \mathrm{m}$ between these results is thought to be caused by the melted solder that gave a pulling-effect in hardening process.

\section{Conclusion}

In order to achieve submicron level bonding for optical modules using $\mathrm{Au} / \mathrm{Sn}$ technique, improvement in the accuracy of fiducial mark recognition and implemented countermeasures against vibration and thermal expansion are effective and essential. Moreover, an automatic calibration function which maintains submicron level bonding even in an environment where some temperature variations are present. Bonding accuracy within the tolerance of $0.1 \mu \mathrm{m}$ has been achieved at room temperature. And, for soldering op-

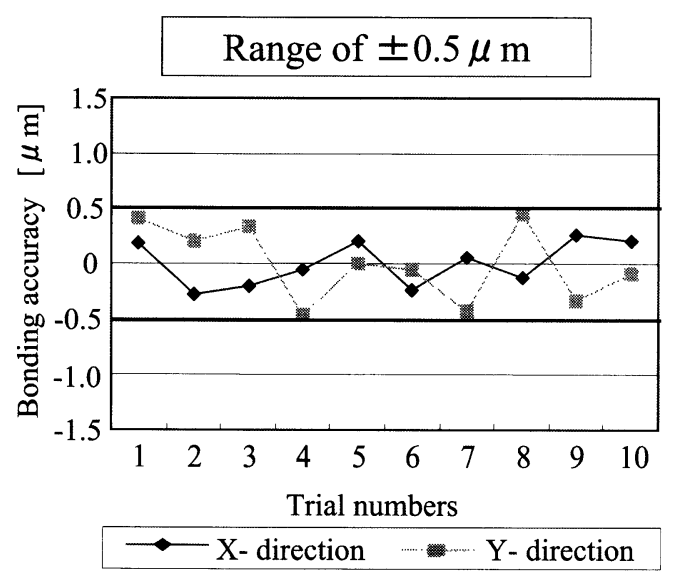

Fig. 21 Bonding accuracy at $300^{\circ} \mathrm{C}$

erations using TEG chips, bonding accuracy within the tolerance from $\pm 0.3 \mu \mathrm{m}$ to $\pm 0.5 \mu \mathrm{m}$ has been achieved. It is proven from the experimental results, however, that heating and soldering still affect bonding accuracy. Making the best use of the calibration method as presented in this paper, a day operation can be maintained with automatic calibration against such inevitable temperature variation and secure bonding accuracy of submicron level without fail.

The next step in the development of these technologies is to go beyond optical module bonding and to apply these high-accuracy bonding technologies as presented here, for other fields, such as for MEMS and 3D semiconductor packages.

(2002.1.7-受理)

\section{References}

1) R. Kaku, T. Maezawa, K. Takayama, A. Hirai, A. Kuroda and T. Harada: "Si V-groove Substrate for Optical Modules", IEMT/IMC Symposium proceedings, pp. 13-17, April 16-18, 1997

2) T. Nakamura: "Surface Mount Type LD Module using Transfer Molding", IEMT/IMC Symposium proceedings, pp. 22-25, April 16-18, 1997

3) A. Yamauchi: "Submicron Flip Chip Bonding Technology for Opto-electronic Devices", ECTC Proceedings, pp. 1743-1746, May 21-24, 2000

4) A. Yamauchi: "Analysis and Measures Against Heat-expansion for Sub-micron LD Assembly by Passive Alignment", ECTC Proceedings, pp. S07-5, May 29-June 1, 2001 